\title{
Joint Effects of Body Mass Index and Waist Circumference on the Incidence of Hypertension in a Community-Based Chinese Population
}

\author{
Mohetaboer Momin Fangfang Fan Jianping Li Jia Jia Long Zhang \\ Yan Zhang Yong Huo
}

Department of Cardiology, Peking University First Hospital, Beijing, China

\section{Keywords}

Chinese $\cdot$ Hypertension · Body mass index . Waist circumference $\cdot$ Obesity

\begin{abstract}
Objective: We aimed to investigate the relationships of body mass index (BMI), waist circumference (WC), and obesity defined using a combination of both indexes, with the incidence of hypertension in a Chinese community-based population. Methods: A total of 1,927 Chinese participants (57.2 \pm 8.9 years old) with normal blood pressure at baseline were recruited from the Shijingshan community in Beijing. Incident hypertension was defined as blood pressure $\geq 140 / 90 \mathrm{~mm} \mathrm{Hg}$, self-reported hypertension, or the use of any antihypertensive medication at the follow-up visit. Results: During 2.3 years of follow-up, 19.1\% $(n=97)$ of the men and $13.6 \%(n=158)$ of the women developed incident hypertension. The adjusted odds ratios (ORs) (95\% confidence intervals [Cls]) for obesity (BMI $\geq 30)$ were 3.49 (1.59-7.66) and 2.60 (1.48-4.55) for men and women, respectively. A 1-point increase in BMI was associated with $8 \%(\mathrm{OR}=1.08,95 \% \mathrm{Cl}: 1.00-1.17)$ and $10 \%(\mathrm{OR}=1.10,95 \% \mathrm{Cl}: 1.05-1.16)$ increases in the incidence of hypertension in men and women, respectively. Abdominal obesity (WC $\geq 90 \mathrm{~cm}$ in men and $\geq 85 \mathrm{~cm}$ in women) was positively associated with incident hypertension in both men (adjusted $\mathrm{OR}=1.79,95 \% \mathrm{Cl}: 1.10-2.91$ ) and women (adjusted $\mathrm{OR}=1.61,95 \% \mathrm{Cl}: 1.09-2.40$ ). A $1-\mathrm{cm}$ increase in WC was associated with $4 \%$ (adjusted OR $=1.04,95 \% \mathrm{Cl}: 1.01-1.07$ ) and $4 \%$ (adjusted $\mathrm{OR}=1.04,95 \% \mathrm{Cl}: 1.02-1.07$ ) increases in the incidence of hypertension in men and
\end{abstract}


women, respectively. The combination of abnormal BMI and WC has the highest risk for hypertension in both men (adjusted $\mathrm{OR}=3.10,95 \% \mathrm{Cl}: 1.48-6.50$ ) and women (adjusted OR = $2.51,95 \% \mathrm{Cl}: 1.43-4.40)$. Conclusions: This study shows that BMI, WC, and an index that combined the two are independently associated with incident hypertension in a Chinese community-based population.

\section{Introduction}

Cardiovascular disease (CVD) is now the leading cause of disability and death among Chinese adults. Hypertension is the most important modifiable risk factor for CVD and total mortality in the Chinese population. Data from the Patient-Centered Evaluative Assessment of Cardiac Events (PEACE) Million Persons Project indicated that $44.7 \%$ of the Chinese adult population aged above 35 years had hypertension $[1,2]$. In addition, an obesity epidemic is occurring in China alongside its rapid socioeconomic development, which is due to the increasing availability of food, a reduction in physical activity, and other changes in lifestyle. Indeed, the 2005 China National Nutrition and Health Survey showed that $23.2 \%$ of Chinese were overweight and obese [3].

Body mass index (BMI) and waist circumference (WC) are commonly recommended as measures of obesity in clinical guidelines. Numerous previous studies have shown that overall obesity, defined using BMI, and central obesity, defined using WC, are associated with incident hypertension [4,5]. Previous studies have frequently investigated the impacts of overall and central obesity separately, however, not everyone with obesity has both high BMI and WC, instead, some may have a normal BMI but an abnormal WC, or a normal WC but an abnormal BMI. A cohort study of US adults found that high WC may not be related to BMI, which suggests that a combination of BMI and WC may be a better predictor of obesity-related disease than BMI or WC alone [6]. Subsequently, other studies have shown that approximately two-thirds of obesity cases would go undiagnosed if WC were not measured in China [7,8]. These findings emphasize the importance of using both BMI and WC to define categories of obesity that predict obesity-related hypertension.

China has been undergoing rapid social changes in recent years that have altered the burden of hypertension, which can be explained by changes in prevalence of the various risk factors. Therefore, the use of current estimates of the incidence of hypertension and of the modifiable risk factors for hypertension in China are critically important for the targeting of limited resources in national programs for hypertension prevention and treatment. Therefore, the primary aim of the present study was to investigate the relationships of BMI, WC, and a combination of the two indexes with new-onset hypertension in a community-based Chinese cohort.

\section{Materials and Methods}

\section{Participants}

The participants were from the Gucheng and Pingguoyuan communities of the Shijingshan district in Beijing, China, who were participants in an atherosclerosis cohort survey performed between December 2011 and April 2012. The methods and primary outcomes of this survey have been reported elsewhere [9]. Initially, 9,540 residents aged $\geq 40$ years were recruited either by responding to recruitment posters or via phone calls if their medical records were held in community health centers between December 2011 and April 2012. In 2014, 5,962 of 
Momin et al.: Obesity and Incidence of Hypertension

the participants for whom gene chip data were available were invited for a follow-up visit that took place between May and July 2014, and 3,823 (64.1\%) of them responded positively and attended. The nonresponders did not differ substantially from the responders with regard to their baseline characteristics (online suppl. Table S1; for all online suppl. material, see www. karger.com/doi/10.1159/000506689). We excluded participants for whom BMI and WC data were unavailable and those who were already hypertensive at baseline. Finally, 1,927 eligible participants were included in the analysis (a flowchart is shown as online suppl. Fig. S1).

This study was approved by the Ethics Committee of Peking University and Peking University First Hospital and each participant provided written informed consent before their enrollment. The study conformed with the principles of the Declaration of Helsinki and the procedures followed were in accordance with institutional guidelines.

\section{Data Collection}

Baseline data were collected in 2011-2012 during a single visit to a clinic by trained research staffs, according to standard operating procedures. The participants were interviewed using a standardized questionnaire that was specifically designed for the present study, to obtain information regarding sociodemographic status, education, occupation, diet, lifestyle, health behavior, medical history, and use of medication. "Current smoking" was defined as smoking one cigarette per day for at least the preceding 6 months. "Current drinking" was defined as drinking once per week for at least the preceding 6 months. Diabetes was defined by a self-reported history, fasting blood glucose (FBG) $\geq 7 \mathrm{mmol} / \mathrm{L}$, or 2-h blood glucose during an oral glucose tolerance test (OGTT) $\geq 11.1 \mathrm{mmol} / \mathrm{L}$. Dyslipidemia was defined by a self-reported history or an abnormal lipid profile. CVD was defined by a selfreported history of coronary heart disease, myocardial infarction, stroke, or transient ischemic attack.

\section{Blood Sample Collection and Laboratory Methods}

A forearm venous blood sample was obtained from each participant after an overnight fast of at least $12 \mathrm{~h}$. Serum or plasma were separated within 30 min of collection and were stored at $-80^{\circ} \mathrm{C}$. FBG and standard 75 -g OGTT blood glucose, lipid profile, and serum creatinine at baseline were measured using a Roche C8000 Automatic Analyzer at the laboratory of the Chinese PLA General Hospital. The estimated glomerular filtration rate (eGFR) was calculated using the Modification of Diet in Renal Disease (MDRD) equation.

\section{Anthropometric Measurements}

Anthropometric measurements, including height, weight, and WC, were obtained using World Health Organization (WHO) standard operating procedures. Height was measured without shoes to the nearest $0.1 \mathrm{~cm}$ using a portable stadiometer. Weight was measured using scales, with participants wearing light indoor clothing and no shoes, to the nearest $0.1 \mathrm{~kg}$. BMI was calculated as weight $/$ height $^{2}\left(\mathrm{~kg} / \mathrm{m}^{2}\right)$. The BMI classes used were those in the WHO guidelines (overweight: BMI $\geq 25$ and $<30$; obesity: BMI $\geq 30$ ). WC was measured as the minimum circumference between the inferior margin of the ribcage and the crest of the ileum. WC was used to determine obesity ( $\geq 90 \mathrm{~cm}$ for males and $\geq 85 \mathrm{~cm}$ for females) according to the recommendations of the Chinese Society of Cardiology [10]. In addition to using BMI and WC to diagnose overall and central obesity, respectively, a combination of BMI and WC was used to create three new obesity categories as follows: Group 1 (both BMI and WC are below the obesity threshold): $\mathrm{BMI}<30$ and $\mathrm{WC}<90 \mathrm{~cm}$ for men and $<85 \mathrm{~cm}$ for women; Group 2 (either BMI or WC are above the obesity threshold): BMI $<30$ and $\mathrm{WC} \geq 90 \mathrm{~cm}$ for men and $\geq 85 \mathrm{~cm}$ for women, or BMI $\geq 30$ and $\mathrm{WC}<90 \mathrm{~cm}$ for men and $<85 \mathrm{~cm}$ for women; Group 3 
Momin et al.: Obesity and Incidence of Hypertension

Table 1. A comparison of the baseline characteristics of male and female participants with new-onset hypertension or normal blood pressure

\begin{tabular}{|c|c|c|c|c|c|c|}
\hline \multirow[t]{2}{*}{ Variable } & \multicolumn{3}{|l|}{ Men } & \multicolumn{3}{|l|}{ Women } \\
\hline & $\begin{array}{l}\text { hypertensive } \\
\text { at follow-up } \\
(n=97)\end{array}$ & $\begin{array}{l}\text { normotensive } \\
\text { at follow-up } \\
(n=507)\end{array}$ & $p$ & $\begin{array}{l}\text { hypertensive } \\
\text { at follow-up } \\
(n=158)\end{array}$ & $\begin{array}{l}\text { normotensive } \\
\text { at follow-up } \\
(n=1,165)\end{array}$ & $p$ \\
\hline Age, years & $56.6 \pm 9.0$ & $55.5 \pm 7.7$ & 0.185 & $56.6 \pm 8.5$ & $53.1 \pm 7.0$ & $<0.001$ \\
\hline BMI & $26.6 \pm 2.9$ & $25.4 \pm 3.0$ & $<0.001$ & $26.4 \pm 4.0$ & $24.9 \pm 3.2$ & $<0.001$ \\
\hline Waist, cm & $87.6 \pm 7.5$ & $84.5 \pm 7.3$ & $<0.001$ & $82.0 \pm 8.1$ & $78.1 \pm 7.5$ & $<0.001$ \\
\hline SBP, mm Hg & $130.1 \pm 6.8$ & $124.2 \pm 8.9$ & $<0.001$ & $129.6 \pm 7.5$ & $120.9 \pm 9.9$ & $<0.001$ \\
\hline $\mathrm{DBP}, \mathrm{mm} \mathrm{Hg}$ & $76.1 \pm 7.5$ & $73.2 \pm 7.6$ & $<0.001$ & $72.7 \pm 7.7$ & $70.3 \pm 7.3$ & $<0.001$ \\
\hline $\mathrm{eGFR}, \mathrm{mL} / \mathrm{min}$ & $93.7 \pm 11.31$ & $94.4 \pm 11.6$ & 0.571 & $95.6 \pm 13.2$ & $99.3 \pm 10.3$ & $<0.001$ \\
\hline Current smoking, $n(\%)$ & $54(55.7)$ & $290(57.2)$ & 0.781 & $6(3.8)$ & $35(3.0)$ & 0.585 \\
\hline Current drinking, $n(\%)$ & $60(61.9)$ & 277 (54.6) & 0.190 & $10(6.3)$ & $94(8.0)$ & 0.451 \\
\hline Dyslipidemia, $n(\%)$ & $71(73.2)$ & 311 (61.3) & 0.029 & $119(75.3)$ & $778(66.8)$ & 0.033 \\
\hline Diabetes mellitus, $n(\%)$ & $23(23.7)$ & $114(22.5)$ & 0.792 & $34(21.5)$ & $116(10.0)$ & $<0.001$ \\
\hline CVD, $n(\%)$ & $9(9.3)$ & $33(6.5)$ & 0.381 & $14(8.9)$ & $53(4.5)$ & 0.031 \\
\hline Lipid-lowering drugs, $n(\%)$ & $6(6.2)$ & $31(6.2)$ & 0.990 & $14(8.9)$ & $52(4.5)$ & 0.029 \\
\hline Glucose-lowering drugs, $n(\%)$ & $5(5.2)$ & $55(10.9)$ & 0.096 & $13(8.2)$ & $43(3.7)$ & 0.018 \\
\hline
\end{tabular}

BMI, body mass index; SBP, systolic blood pressure; DBP, diastolic blood pressure; eGFR, estimated glomerular filtration rate; CVD, cardiovascular disease.

(both BMI and WC are above the obesity threshold): BMI $\geq 30$ and WC $\geq 90 \mathrm{~cm}$ for men and $\geq 85 \mathrm{~cm}$ for women.

\section{Brachial Blood Pressure}

Peripheral systolic/diastolic blood pressure (SBP/DBP) was measured in each participant while seated and after a 5-min rest, using an Omron HEM-7117 electronic sphygmomanometer that had undergone standard calibration, and appropriately sized cuffs. Triplicate measurements were performed using the right arm, with $\geq 1$ min between successive readings. Resting pulse rate was measured simultaneously. The SBP and DBP used in the analysis were calculated as the mean of the three consecutive measurements for each patient.

\section{Follow-Up Examinations and Outcomes}

The follow-up examination was conducted in 2014. Three blood pressure measurements were made according to the same standard protocol used at the baseline examination. The use of antihypertensive medications was recorded using a standard questionnaire. "Newonset hypertension" was defined by an SBP $\geq 140 \mathrm{~mm} \mathrm{Hg}$ and/or a DBP $\geq 90 \mathrm{~mm} \mathrm{Hg}$, selfreported hypertension, or the use of any antihypertensive medication at the time of the follow-up survey, in those participants who were normotensive at baseline.

\section{Statistical Analysis}

All the statistical analyses were performed separately for each sex. Categorical variables are expressed as numbers and percentages. Continuous variables are described using means and standard deviations for normally distributed data and medians for non-normally distributed data. Univariate comparisons were made between groups using ANOVA for continuous variables and the $\chi^{2}$ test for categorical variables. Univariate and multivariate analyses were performed to determine the relationships between obesity categories and the incidence of hypertension. The multivariable regression model was adjusted for other vari- 
Momin et al.: Obesity and Incidence of Hypertension

Table 2. Univariate and multivariate regression analysis of the relationship between BMI category and the risk of hypertension, classified according to sex

\begin{tabular}{|c|c|c|c|c|c|c|}
\hline & \multirow[t]{2}{*}{$n$} & \multirow[t]{2}{*}{ Incidence, $n(\%)$} & \multicolumn{2}{|l|}{ Crude analysis } & \multicolumn{2}{|c|}{ Multivariate analysis } \\
\hline & & & OR $(95 \% \mathrm{CI})$ & $p$ & OR $(95 \% \mathrm{CI})$ & $p$ \\
\hline \multicolumn{7}{|l|}{ Men } \\
\hline BMI (per 1 point) & & & $1.14(1.06-1.23)$ & $<0.001$ & $1.08(1.00-1.17)$ & 0.048 \\
\hline $\mathrm{BMI}<25$ & 260 & $28(10.8)$ & 1 & & 1 & \\
\hline $\mathrm{BMI} \geq 25$ and $<30$ & 300 & $53(17.6)$ & 1.78 (1.09-2.91) & 0.022 & $1.40(0.82-2.37)$ & 0.215 \\
\hline $\mathrm{BMI} \geq 30$ & 44 & $16(36.4)$ & $4.73(2.28-9.81)$ & $<0.001$ & $3.49(1.59-7.66)$ & 0.002 \\
\hline \multicolumn{7}{|l|}{ Women } \\
\hline BMI (per 1 point) & & & 1.13 (1.07-1.18) & $<0.001$ & $1.10(1.05-1.16)$ & $<0.001$ \\
\hline $\mathrm{BMI}<25$ & 678 & $60(8.9)$ & 1 & & 1 & \\
\hline $\mathrm{BMI} \geq 25$ and $<30$ & 537 & $73(13.6)$ & $1.62(1.13-2.33)$ & 0.009 & $1.21(0.82-1.79)$ & 0.337 \\
\hline $\mathrm{BMI} \geq 30$ & 108 & $25(23.2)$ & $3.10(1.84-5.22)$ & $<0.001$ & $2.60(1.48-4.55)$ & $<0.001$ \\
\hline
\end{tabular}

The data were adjusted for age, estimated glomerular filtration rate, currentsmoking, current drinking, diabetes, dyslipidemia, baseline systolic blood pressure, cardiovascular disease, antidiabetic drug use, and lipid-lowering drug use.

ables, including age, sex, eGFR, current smoking, current drinking, diabetes, dyslipidemia, baseline SBP, CVD, antidiabetic drug use, and lipid-lowering drug use. Analyses were performed using Empower ${ }^{\circledR}$ (www.empowerstats.com, X\&Y solutions, Inc., Boston, MA, USA) and R (http://www.R-project.org). $p<0.05$ was considered to represent statistical significance.

\section{Results}

The baseline characteristics of the 1,927 participants, classified by sex, are shown in Table 1 . They were $54.2 \pm 7.5$ years old and $31.3 \%$ were male. Their median BMI was $25.3 \pm$ 3.2 , and their median WC was $80.6 \pm 8.2 \mathrm{~cm}$. The median follow-up time was 2.3 years. During the follow-up period, $19.1 \%(n=97)$ of the men and $13.6 \%(n=158)$ of the women developed hypertension. The incidence of hypertension was higher in participants who had higher blood pressures at baseline, in those with dyslipidemia, and in those with high BMI and WC, in both men and women. Compared with normotensive participants, those with new-onset hypertension were older, had lower eGFR, were more likely to have diabetes, and, if female, were more likely to have reported CVD and higher usage of glucose- and lipid-lowering drugs.

Univariate and multivariate analyses were carried out to determine whether BMI and WC were independently associated with the incidence of hypertension, after adjustment for likely confounding factors. The odds ratios (ORs) for the risk of hypertension increased with BMI and WC category. Compared with normal BMI, the adjusted ORs (95\% confidence intervals [CIs]) for obesity (BMI $\geq 30)$ were 3.49 (1.59-7.66) and 2.60 (1.48-4.55) for men and women, respectively. A 1-point increase in BMI was associated with 8\% (adjusted OR $=1.08,95 \% \mathrm{CI}$ : $1.00-1.17$ ) and $10 \%$ (adjusted $\mathrm{OR}=1.10,95 \% \mathrm{CI}: 1.05-1.16$ ) increases in the incidence of hypertension in men and women, respectively (Table 2). Compared with participants with normal WC, abdominal obesity ( $\mathrm{WC} \geq 90 \mathrm{~cm}$ in men and $\geq 85 \mathrm{~cm}$ in women) was positively associated with the incidence of hypertension in both men (adjusted OR $=1.79,95 \%$ CI: 1.10 2.91 ) and women (adjusted $\mathrm{OR}=1.61,95 \% \mathrm{CI}: 1.09-2.40)(p<0.05)$. A $1-\mathrm{cm}$ increase in WC was associated with $4 \%$ (adjusted $\mathrm{OR}=1.04,95 \% \mathrm{CI}: 1.01-1.07$ ) and $4 \%$ (adjusted $\mathrm{OR}=1.04$, 95\% CI: 1.02-1.07) increases in the incidence of hypertension in men and women, respectively (Table 3). 
Table 3. Univariate and multivariate regression analysis of the relationship between waist circumference category and the risk of hypertension, classified according to sex

\begin{tabular}{|c|c|c|c|c|c|c|}
\hline & \multirow[t]{2}{*}{$n$} & \multirow[t]{2}{*}{ Incidence, $n(\%)$} & \multicolumn{2}{|l|}{ Crude analysis } & \multicolumn{2}{|c|}{ Multivariate analysis } \\
\hline & & & OR $(95 \% \mathrm{CI})$ & $p$ & OR $(95 \% \mathrm{CI})$ & $p$ \\
\hline \multicolumn{7}{|l|}{ Men } \\
\hline Waist (per $1 \mathrm{~cm}$ ) & & & 1.06 (1.03-1.09) & $<0.001$ & $1.04(1.01-1.07)$ & 0.018 \\
\hline Waist $<90 \mathrm{~cm}$ & 436 & $57(13.1)$ & 1 & & 1 & \\
\hline Waist $\geq 90 \mathrm{~cm}$ & 168 & $40(23.8)$ & $2.08(1.32-3.26)$ & 0.001 & $1.79(1.10-2.91)$ & 0.019 \\
\hline \multicolumn{7}{|l|}{ Women } \\
\hline Waist (per $1 \mathrm{~cm}$ ) & & & 1.07 (1.04-1.09) & $<0.001$ & $1.04(1.02-1.07)$ & $<0.001$ \\
\hline Waist $<85 \mathrm{~cm}$ & 1,060 & $107(10.1)$ & 1 & & 1 & \\
\hline Waist $\geq 85 \mathrm{~cm}$ & 263 & $51(19.4)$ & $2.14(1.49-3.09)$ & $<0.001$ & $1.61(1.09-2.40)$ & 0.018 \\
\hline
\end{tabular}

The data were adjusted for age, estimated glomerular filtration rate, current smoking, currentdrinking, diabetes, dyslipidemia, baseline systolic blood pressure, cardiovascular disease, antidiabetic drug use, and lipid-lowering drug use.

Table 4. Univariate and multivariate regression analysis of the relationship between obesity category, defined using a combination of BMI and WC, and the risk of hypertension, classified according to sex

\begin{tabular}{|c|c|c|c|c|c|c|}
\hline \multirow[t]{2}{*}{ Variable } & \multirow[t]{2}{*}{$n$} & \multirow{2}{*}{$\begin{array}{l}\text { Incidence of } \\
\text { hypertension, } \\
n(\%)\end{array}$} & \multicolumn{2}{|l|}{ Crude model } & \multicolumn{2}{|c|}{ Multivariate analysis } \\
\hline & & & OR $(95 \% \mathrm{CI})$ & $p$ value & OR $(95 \%$ CI $)$ & $p$ value \\
\hline \multicolumn{7}{|l|}{ Men } \\
\hline G1 & 434 & $56(12.9)$ & 1 & & 1 & \\
\hline G2 & 128 & $26(20.3)$ & $1.72(1.03-2.88)$ & 0.039 & $1.47(0.84-2.55)$ & 0.177 \\
\hline G3 & 42 & $15(35.7)$ & $3.75(1.88-7.48)$ & $<0.001$ & $3.10(1.48-6.50)$ & 0.003 \\
\hline$p$ for $\mathrm{tr}$ & & & $<0.001$ & & 0.003 & \\
\hline \multicolumn{7}{|c|}{ Women } \\
\hline G1 & 1,043 & $104(10.0)$ & 1 & & 1 & \\
\hline G2 & 189 & 32 (16.9) & $1.84(1.20-2.83)$ & 0.006 & $1.31(0.82-2.09)$ & 0.265 \\
\hline G3 & 91 & $22(24.2)$ & $2.88(1.71-4.85)$ & $<0.001$ & $2.51(1.43-4.40)$ & 0.001 \\
\hline$p$ for $\mathrm{tr}$ & & & $<0.001$ & & 0.002 & \\
\hline
\end{tabular}

Men: G1 (BMI <30, WC $<90 \mathrm{~cm})$; G2 (BMI <30, WC $\geq 90 \mathrm{~cm})$ or $(\mathrm{BMI} \geq 30$, WC $<90 \mathrm{~cm})$; G3 (BMI $\geq 30$, WC $\geq 90 \mathrm{~cm})$. Women: G1 $(\mathrm{BMI}<30, \mathrm{WC}<85 \mathrm{~cm})$; G2 $(\mathrm{BMI}<30, \mathrm{WC} \geq 85 \mathrm{~cm})$ or $(\mathrm{BMI} \geq 30, \mathrm{WC}<85 \mathrm{~cm})$; G3 $(\mathrm{BMI} \geq 30, \mathrm{WC} \geq 85 \mathrm{~cm})$. The data were adjusted for age, estimated glomerular filtration rate, current smoking, current drinking, diabetes, dyslipidemia, baseline systolic blood pressure, cardiovascular disease, antidiabetic drug use, and lipid-lowering drug use. WC, waist circumference; BMI, body mass index; OR, odds ratio; $\mathrm{CI}$, confidence interval.

In the univariate and multivariate regression analysis of the relationship between obesity category (defined using a combination of BMI and WC) and the risk of hypertension, the risk of developing hypertension increased according to obesity category for both sexes ( $p$ for trend $<0.001$ ). However, compared with the all normal group, the combination of abnormal BMI and WC had the strongest predictive value (Table 4) for hypertension in both men (adjusted OR $=3.10,95 \% \mathrm{CI}: 1.48-6.50$ ) and women (adjusted OR $=2.51,95 \% \mathrm{CI}: 1.43-$ 4.40). 
Momin et al.: Obesity and Incidence of Hypertension

\section{Discussion}

This study has confirmed that both high BMI and WC are associated with a higher incidence of hypertension in urban Chinese men and women. Furthermore, we have used a combination of BMI and WC to create two further obesity categories for the evaluation of the relationship between obesity and hypertension risk, to better identify all the subgroups of obese people at high risk of hypertension. Using this classification, we have shown that the combination of abnormal BMI and WC has the highest risk for hypertension. Specifically, participants with BMIs below the obesity threshold but obese WC values, and those with nonobese $\mathrm{WC}$ values but obese BMI values showed a trend of increasing risk for developing hypertension as well.

A relationship between obesity and hypertension has been proposed by multiple researchers. The results of the present study are consistent with most of the findings of previous longitudinal studies conducted in Chinese populations. For example, a study of 53,028 normotensive Chinese people who were followed for 6.38 years showed that those with BMI $\geq 28$ had a relative risk of hypertension of 3.13 (95\% CI: 2.84-3.45) compared with those who had a BMI <22 [11]. Second, a cohort study of 9,905 Chinese participants showed a significant upward trend in the incidence of hypertension with increasing BMI, WC, and waistto-height ratio (WHtR). In this study, BMI and WHtR had larger areas under the receiver operating characteristic (ROC) curve for the identification of hypertension in both sexes [12]. Third, a prospective study of a population-based sample of 24,360 rural Chinese adults showed that overweight and obesity was an independent predictor of hypertension in both sexes (HR = 1.28, 95\% CI: 1.17-1.40) [13]. Fourth, a population-based sample of 10,525 Chinese adults that was followed up for 8 years also showed that BMI is an independent predictor of hypertension [14]. Zheng et al. [15] reported similar results in rural Chinese women. Furthermore, the large-scale Kailuan study showed that WC is an independent predictor of hypertension [16], and Niu and Seo [17] reported the same finding after 12 years of follow-up, WC increases the risk for developing hypertension later in life even after adjustment for overall obesity.

In comparison, most of these prior studies of Chinese populations were conducted in rural areas, whereas the present study was of a community-based urban population. In addition, most of the previous studies were of a healthy population with a large age range and a lower risk for CVD, whereas the present population was older and had a higher risk of CVD. The median duration of follow-up in the present study was 2.3 years; therefore, the incidence of new-onset hypertension was relatively low, but similar results were obtained to those of previous studies. The percentage of participants that were overweight or obese, according to BMI, was $51.3 \%$, and the percentages with central obesity, according to WC, were 38.5 and $24.7 \%$ for men and women, respectively, which are higher than previously published due to urban population. Besides, more additional factors that might have contributed to hypertension were taken into account in the present study compared to previous studies. However, the ORs for hypertension for BMI and WC were comparable to previously reported figures. Many studies conducted in other Asian populations have yielded similar results [18-24], but others have yielded different outcomes. For example, a study of 1,718 Korean people who were followed up for 2.8 years showed that WC and WHtR were associated with the risk of hypertension, but BMI was not [25]. A second study of 4,454 Koreans who were followed up for 4 years found that WC, WHR, and WHtR were better than BMI for the prediction of hypertension [26]. In European and American populations, most of the prospective studies showed a positive correlation between obesity and the risk of hypertension [27-36].

Other previous studies have tended to investigate the relationships between different indexes of obesity and the risk of hypertension separately; therefore, it is difficult to compare the predictive value of each directly. The most recently published meta-analysis included data from 59 studies and showed positive associations of BMI, WC, and WhtR with the incidence of 
hypertension. In subgroup analysis, BMI remained a predictor, irrespective of age, ethnicity, sex, and BMI subgroup. However, WC only predicted hypertension in women, older people, and Asians [37]. Another recent meta-analysis of the findings of 23 longitudinal observation studies showed that both BMI $\geq 30$ and WC $\geq 102 / 88 \mathrm{~cm}$ (ATPIII criteria) predicted the development of hypertension. However, in the subgroup analysis, only $W C \geq 102 / 88 \mathrm{~cm}$, and not BMI $\geq 30$, predicted the development of hypertension in Hispanics/Latinos. Furthermore, interestingly, neither BMI $\geq 30$ nor WC $\geq 102 / 88 \mathrm{~cm}$ was a significant predictor of hypertension when the data were corrected for age [4]. In addition, a meta-analysis published in 2017 showed that there was a nonlinear association between WC and the risk of hypertension, with a steeper increase in risk at lower WCs [38]. Another meta-analysis of studies that used ROC curves to compare the predictive power of indices of obesity for hypertension showed that WHtR was significantly better than WC and BMI [5]. However, no anthropometric variable was systematically better than others at predicting hypertension in a meta-analysis that included Asian populations [39]. Thus, in summary, obesity is a predictor of hypertension, but the optimal index varies according to the sex, ethnicity, and age of the individuals concerned.

We have shown that the prevalence of central obesity with a normal BMI is $13.0 \%$ in women and $20.9 \%$ in men, that of overall obesity with a normal WC is $1.3 \%$ in women and $0.3 \%$ in men, and that of both overall and central obesity is $6.9 \%$ in women and $7.0 \%$ in men. This implies that if only one index is used, a proportion of obese people will not be included. However, there have been very few studies that have avoided this problem by using both indexes. A study of 9,174 rural Chinese participants showed that those with high BMI and WC showed the highest risk of hypertension, irrespective of sex. Women who were 18-39 years old and who had a nonobese BMI but a high WC showed a 1.96-fold higher risk of hypertension, and women who were 40-59 years old and had a high BMI but a nonobese WC also had a higher risk of hypertension, compared with women with nonobese BMI and WC [40]. Another study showed that the risk of hypertension among the three types of obesity in adults in urban areas was both central and general obesity $>$ general obesity only $>$ central obesity only, and in adults in rural areas it was both central and general obesity > central obesity only $>$ general obesity only [8]. Thus, each index has both advantages and disadvantages. Furthermore, BMI is not capable of differentiating between individuals with excess fat and those with high muscle mass, nor between individuals with differing fat distribution. Therefore, individuals with differing muscle and fat distribution will be assigned the same risk of CVD if BMI alone is used. Currently, WC is widely used to assess abdominal obesity. However, WC strongly correlates with body mass and BMI; therefore, it cannot replace BMI for the prediction of mortality and health risks. Furthermore, WC does not take into account differences in height. The present study provides evidence to suggest that both indexes should be used to evaluate the risk of hypertension, to circumvent the limitations of the use of each alone.

The study had several limitations. First, the study sample was from an urban community in northern China, and therefore, the conclusions cannot be generalized to populations in other regions. Second, the sample sizes of some of the subgroups were relatively small, and the duration of follow-up was short compared with those of other studies, which may have affected the statistical power of the analyses. Therefore, a larger study sample and a longer follow-up period should be used in the future. Third, new-onset hypertension was defined using blood pressure, self-reported hypertension, or the use of any antihypertensive medication at the follow-up visit, for those participants who were normotensive at baseline. Their blood pressure was measured only on one occasion at follow-up, instead of on more separate occasions, which may have resulted in some participants being classified incorrectly; however, this method was the same as that used in most of the prior epidemiologic studies. Finally, other risk factors, such as diet and exercise habits and family history, were not taken into account in the analysis. 
In conclusion, $\mathrm{BMI}, \mathrm{WC}$, and a combination of BMI and WC were independently associated with the subsequent development of hypertension. These findings imply that it is important to identify the specific obesity category of each patient, using both BMI and WC, to accurately predict obesity-related hypertension. Furthermore, they support the clinical importance of maintaining both BMI and WC within their normal ranges to reduce such risk. The use of this combination of indexes is a simple and cost-effective method that provides a statistically superior prediction of obesity-related hypertension. Its use may encourage earlier targeted interventions and reduce the financial cost of treating this disease and its complications.

\section{Acknowledgement}

The authors thank all the study team members for their participation. We are especially grateful to the site managers of Gucheng and Pingguoyuan Community Health Centers for their support. We also thank Mark Cleasby, PhD, from Liwen Bianji, Edanz Group China (www. liwenbianji.cn/ac), for editing the English text of a draft of the manuscript.

\section{Statement of Ethics}

This study was approved by the Ethics Committee of Peking University and Peking University First Hospital and each participant provided written informed consent before their enrollment. The study conformed with the principles of the Declaration of Helsinki and the procedures followed were in accordance with institutional guidelines.

\section{Disclosure Statement}

The authors have no conflicts of interest to declare.

\section{Funding Sources}

This work was supported by the National Key Research and Development Program of China (grant No. 2016YFC0903103), the University of Michigan-Peking University Health Science Center (UM-PUHSC) Joint Institute for Translational and Clinical research (grant No. BMU20110177 and BMU20160530), the Fundamental Research Funds for the Central Universities, the Beiijng Lisheng Cardiovascular Health Foundation, Projects of the National Natural Science Foundation of China (grant No. 81703288), Scientific Research Seed Fund of Peking University First Hospital (grant No. 2018SF003 and 2018SF072).

\section{Author Contributions}

M.M. participated in the design of the study, performed the statistical analysis, and drafted the manuscript. J.J. and L.Z. participated in the epidemiologic survey and the data management, and helped to draft the manuscript. J.L. participated in the study design and helped to draft the manuscript. F.F. participated in implementing the investigation, the data analysis, and drafting the manuscript. Y.H. and Y.Z. conceived the study, participated in its design and coordination, and helped to analyze the data and draft the manuscript. All authors read and approved the final manuscript. 
Momin et al.: Obesity and Incidence of Hypertension

\section{References}

1 Wu Y, Huxley R, Li L, Anna V, Xie G, Yao C, et al.; China NNHS Steering Committee; China NNHS Working Group. Prevalence, awareness, treatment, and control of hypertension in China: data from the China National Nutrition and Health Survey 2002. Circulation. 2008 Dec;118(25):2679-86.

2 Lu J, Lu Y, Wang X, Li X, Linderman GC, Wu C, et al. Prevalence, awareness, treatment, and control of hypertension in China: data from 1.7 million adults in a population-based screening study (China PEACE Million Persons Project). Lancet. 2017 Dec;390(10112):2549-58.

$3 \mathrm{Wu} \mathrm{YF,} \mathrm{Ma} \mathrm{GS,} \mathrm{Hu} \mathrm{YH,} \mathrm{Li} \mathrm{YP,} \mathrm{Li} \mathrm{X,} \mathrm{Cui} \mathrm{ZH,} \mathrm{et} \mathrm{al.} \mathrm{[The} \mathrm{current} \mathrm{prevalence} \mathrm{status} \mathrm{of} \mathrm{body} \mathrm{overweight} \mathrm{and} \mathrm{obesity}$ in China: data from the China National Nutrition and Health Survey]. Zhonghua Yu Fang Yi Xue Za Zhi. 2005 Sep;39(5):316-20.

4 Seo DC, Choe S, Torabi MR. Is waist circumference $\geq 102 / 88 \mathrm{~cm}$ better than body mass index $\geq 30$ to predict hypertension and diabetes development regardless of gender, age group, and race/ethnicity? Meta-analysis. Prev Med. 2017 Apr;97:100-8.

5 Lee CM, Huxley RR, Wildman RP, Woodward M. Indices of abdominal obesity are better discriminators of cardiovascular risk factors than BMI: a meta-analysis. J Clin Epidemiol. 2008 Jul;61(7):646-53.

6 Li C, Ford ES, McGuire LC, Mokdad AH. Increasing trends in waist circumference and abdominal obesity among US adults. Obesity (Silver Spring). 2007 Jan;15(1):216-24.

7 Du T, Sun X, Yin P, Huo R, Ni C, Yu X. Increasing trends in central obesity among Chinese adults with normal body mass index, 1993-2009. BMC Public Health. 2013 Apr 10;13:327.

8 Shen C, Zhou Z, Lai S, Tao X, Zhao D, Dong W, et al. Urban-rural-specific trend in prevalence of general and central obesity, and association with hypertension in Chinese adults, aged 18-65 years. BMC Public Health. 2019 May 30;19(1):661.

9 Fan F, Qi L, Jia J, Xu X, Liu Y, Yang Y, et al. Noninvasive Central Systolic Blood Pressure Is More Strongly Related to Kidney Function Decline Than Peripheral Systolic Blood Pressure in a Chinese Community-Based Population. Hypertension. 2016 Jun;67(6):1166-72.

10 Hypertension Study Group of Chinese Society of Cardiology of Chinese Medical Association. [Chinese expert consensus on obesity-related hypertension management]. Zhonghua Xin Xue Guan Bing Za Zhi. 2016 Mar; 44(3):212-9.

11 Qi SF, Zhang B, Wang HJ, Yan J, Du P, Zhang W, et al. Joint effects of age and body mass index on the incidence of hypertension subtypes in the China Health and Nutrition Survey: a cohort study over 22 years. Prev Med. 2016 Aug;89:23-30.

12 Chen X, Liu Y, Sun X, Yin Z, Li H, Deng K, et al. Comparison of body mass index, waist circumference, conicity index, and waist-to-height ratio for predicting incidence of hypertension: the rural Chinese cohort study. J Hum Hypertens. 2018 Mar;32(3):228-35.

13 Sun Z, Zheng L, Detrano R, Zhang X, Xu C, Li J, et al. Incidence and predictors of hypertension among rural Chinese adults: results from Liaoning province. Ann Fam Med. 2010 Jan-Feb;8(1):19-24.

14 Gu D, Wildman RP, Wu X, Reynolds K, Huang J, Chen CS, et al. Incidence and predictors of hypertension over 8 years among Chinese men and women. J Hypertens. 2007 Mar;25(3):517-23.

15 Zheng L, Zhang Z, Sun Z, Li J, Zhang X, Xu C, et al. The association between body mass index and incident hypertension in rural women in China. Eur J Clin Nutr. 2010 Aug;64(8):769-75.

16 Sun H, Zheng M, Wu S, Chen M, Cai J, Yang X. Waist circumference and incidence of hypertension in Chinese adults: Observations from the Kailuan Study. Herz. 2017 Nov;42(7):677-83.

17 Niu J, Seo DC. Central obesity and hypertension in Chinese adults: a 12 -year longitudinal examination. Prev Med. 2014 May;62:113-8.

18 Kanegae H, Oikawa T, Suzuki K, Okawara Y, Kario K. Developing and validating a new precise risk-prediction model for new-onset hypertension: The Jichi Genki hypertension prediction model (JG model). J Clin Hypertens (Greenwich). 2018 May;20(5):880-90.

19 Cheung YB. "A Body Shape Index" in middle-age and older Indonesian population: scaling exponents and association with incident hypertension. PLoS One. 2014 Jan;9(1):e85421.

20 Ishikawa-Takata K, Ohta T, Moritaki K, Gotou T, Inoue S. Obesity, weight change and risks for hypertension, diabetes and hypercholesterolemia in Japanese men. Eur J Clin Nutr. 2002 Jul;56(7):601-7.

21 Ohnishi H, Saitoh S, Akasaka H, Mitsumata K, Chiba M, Furugen M, et al. Incidence of hypertension in individuals with abdominal obesity in a rural Japanese population: the Tanno and Sobetsu study. Hypertens Res. 2008 Jul;31(7):1385-90.

22 Chei CL, Iso H, Yamagishi K, Tanigawa T, Cui R, Imano H, et al. Body fat distribution and the risk of hypertension and diabetes among Japanese men and women. Hypertens Res. 2008 May;31(5):851-7.

23 Fujita M, Sato Y, Nagashima K, Takahashi S, Hata A. Predictive power of a body shape index for development of diabetes, hypertension, and dyslipidemia in Japanese adults: a retrospective cohort study. PLoS One. 2015 Jun;10(6):e0128972.

24 Wang W, Lee ET, Fabsitz RR, Devereux R, Best L, Welty TK, et al. A longitudinal study of hypertension risk factors and their relation to cardiovascular disease: the Strong Heart Study. Hypertension. 2006 Mar;47(3):403-9.

25 Choi JR, Ahn SV, Kim JY, Koh SB, Choi EH, Lee GY, et al. Comparison of various anthropometric indices for the identification of a predictor of incident hypertension: the ARIRANG study. J Hum Hypertens. 2018 Apr;32(4): 294-300. 
26 Lee JW, Lim NK, Baek TH, Park SH, Park HY. Anthropometric indices as predictors of hypertension among men and women aged 40-69 years in the Korean population: the Korean Genome and Epidemiology Study. BMC Public Health. 2015 Feb;15(1):140.

27 Parikh NI, Pencina MJ, Wang TJ, Benjamin EJ, Lanier KJ, Levy D, et al. A risk score for predicting near-term incidence of hypertension: the Framingham Heart Study. Ann Intern Med. 2008 Jan;148(2):102-10.

28 Huang Z, Willett WC, Manson JE, Rosner B, Stampfer MJ, Speizer FE, et al. Body weight, weight change, and risk for hypertension in women. Ann Intern Med. 1998 Jan;128(2):81-8.

29 Folsom AR, Kushi LH, Anderson KE, Mink PJ, Olson JE, Hong CP, et al. Associations of general and abdominal obesity with multiple health outcomes in older women: the Iowa Women's Health Study. Arch Intern Med. 2000 Jul;160(14):2117-28.

30 Diederichs C, Neuhauser H. The incidence of hypertension and its risk factors in the German adult population: results from the German National Health Interview and Examination Survey 1998 and the German Health Interview and Examination Survey for Adults 2008-2011. J Hypertens. 2017 Feb;35(2):250-8.

31 Pereira M, Lunet N, Paulo C, Severo M, Azevedo A, Barros H. Incidence of hypertension in a prospective cohort study of adults from Porto, Portugal. BMC Cardiovasc Disord. 2012 Nov;12(1):114.

32 Bombelli M, Facchetti R, Sega R, Carugo S, Fodri D, Brambilla G, et al. Impact of body mass index and waist circumference on the long-term risk of diabetes mellitus, hypertension, and cardiac organ damage. Hypertension. 2011 Dec;58(6):1029-35.

33 Kristjansson K, Sigurdsson JA, Lissner L, Sundh V, Bengtsson C. Blood pressure and pulse pressure development in a population sample of women with special reference to basal body mass and distribution of body fat and their changes during 24 years. Int J Obes Relat Metab Disord. 2003 Jan;27(1):128-33.

34 Hu G, Barengo NC, Tuomilehto J, Lakka TA, Nissinen A, Jousilahti P. Relationship of physical activity and body mass index to the risk of hypertension: a prospective study in Finland. Hypertension. 2004 Jan;43(1):25-30.

35 Radi S, Lang T, Lauwers-Cancès V, Chatellier G, Fauvel JP, Larabi L, et al.; IHPAF Group. One-year hypertension incidence and its predictors in a working population: the IHPAF study. J Hum Hypertens. 2004 Jul;18(7):48794.

36 Fuchs FD, Gus M, Moreira LB, Moraes RS, Wiehe M, Pereira GM, et al. Anthropometric indices and the incidence of hypertension: a comparative analysis. Obes Res. 2005 Sep;13(9):1515-7.

37 Zhou W, Shi Y, Li YQ, Ping Z, Wang C, Liu X, et al. Body mass index, abdominal fatness, and hypertension incidence: a dose-response meta-analysis of prospective studies. J Hum Hypertens. 2018 May;32(5):321-33.

38 Jayedi A, Rashidy-Pour A, Khorshidi M, Shab-Bidar S. Body mass index, abdominal adiposity, weight gain and risk of developing hypertension: a systematic review and dose-response meta-analysis of more than 2.3 million participants. Obes Rev. 2018 May;19(5):654-67.

39 Obesity in Asia Collaboration. Is central obesity a better discriminator of the risk of hypertension than body mass index in ethnically diverse populations? J Hypertens. 2008 Feb;26(2):169-77.

40 Zhang M, Zhao Y, Wang G, Zhang H, Ren Y, Wang B, et al. Body mass index and waist circumference combined predicts obesity-related hypertension better than either alone in a rural Chinese population. Sci Rep. 2016 Aug;6(1):31935. 